
\title{
Análisis prospectivo del
diseño gráfico en
México
}

\section{Prospective analysis of graphic design in Mexico}

Susana Rodríguez Gutiérrez

srodriguez61@uabc.edu.mx

Universidad Autónoma

de Baja California

Tijuana, Baja California

ORCID: 0000-0002-5674-2586

\author{
Carolina Trejo Alba \\ carolina.trejo@uabc.edu.mx \\ Universidad Autónoma \\ de Baja California \\ Tijuana, Baja California \\ ORCID: 0000-0001-6718-3663
}

\author{
Ervey Leonel Hernández Torres \\ ervey.hernandez@uabc.edu.mx \\ Universidad Autónoma \\ de Baja California \\ Tijuana, Baja California \\ ORCID: 0000-0003-3720-1415
}

Recibido: 18 de diciembre de 2019 Aprobado: 14 de abril de 2020 Publicado: 30 de junio de 2020

\section{Resumen}

El objetivo de esta investigación es el análisis del origen y estado actual del diseño gráfico en México. Por tal razón, son presentados avances científicos y tecnológicos relacionados con esta disciplina. En particular, se exploran horizontes asociados a las ramas como la ingeniería de software y la neurociencia. En virtud de ello se puede comprender el carácter prospectivo del estudio. Llegados a este punto, es preciso señalar que se trata de una investigación documental. Por lo cual, se realiza un estudio de aquellas áreas multidisciplinarias en las cuales el diseñador puede orientarse: el diseño de experiencias de usuario desde la ingeniería de software o en la gestión sustentable de proyectos. Se considera que el diseñador requiere estrechar lazos con la divulgación científica. Por otra parte, una limitante es la ausencia de informes respecto a las competencias y las nuevas especialidades del diseñador gráfico en México. Esta investigación es una oportunidad de discutir las tareas tradicionales del diseño y las nuevas, dadas por el uso intensivo de la tecnología y los modelos de trabajo colaborativo.

Palabras clave: Estudio prospectivo, diseño gráfico, diseño de experiencias, neurociencia, interdisciplinariedad, sustentabilidad.

\section{Abstract}

The objective of this research is the analysis of the origin and current state of graphic design in Mexico. For this reason, scientific and technological advances related to this discipline are presented. In particular, horizons associated with branches such as software engineering and neuroscience are explored. By virtue of this, the prospective nature of the study can be understood. At this point, it should be noted that this is a documentary investigation. Therefore, a study is made of those multidisciplinary areas in which the designer can focus: the design of user experiences from software engineering or sustainable project management. The designer is considered to require closer ties to scientific disclosure. On the other hand, a limitation is the absence of reports regarding the skills and new specialties of the graphic designer in Mexico. This research is an opportunity to discuss traditional design tasks and new ones, given by the intensive use of technology and collaborative work models.

Keywords: Prospective study, graphic design, experience design, neuroscience, interdisciplinarity, sustainability 


\section{Danorama general de la disciplina}

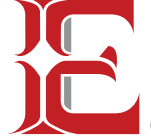

12 de octubre de 1968 fueron inauguradas las Olimpiadas en México, primer país de Latinoamérica, sede de este evento. El desarrollo de la gráfica estuvo a cargo del arquitecto Ramírez Vázquez, presidente del Comité Organizador de los Juegos Olímpicos junto a Lance Wayman. Esta colaboración asentó un antes y un después en el uso del diseño gráfico como un vínculo de comunicación multicultural por primera vez en México (Balcazar, 2019). Esa imagen sigue dado la vuelta al mundo en diferentes exposiciones.

Este evento habría de dar pie a la profesionalización de la disciplina del diseño gráfico en México, de acuerdo con Kloss Fernández del Castillo (2006). Fue la Universidad Iberoamericana en 1968, la primera institución que ofertó este programa de estudios con el grado de licenciatura, y la primera diseñadora en obtener el grado de licenciada fue Ana María Peláez Villegas. Asimismo, se puede hablar de una evolución del diseño con relación a la demanda y la necesidad social, así como de los avances tecnológicos.

Consideremos ahora la situación actual de la industria creativa en México. De acuerdo con diversos despachos de diseño gráfico nacionales se plantea como uno de los objetivos, la profesionalización del diseñador gráfico. Una de las estrategias a plantear es la atención al fondo por encima de la forma, a través de metodologías y de procesos creativos y pragmáticos, como señala Cruz (2018). Otra condición mencionada por estos despachos es la del crecimiento durante los últimos 10 años, impulsado en gran parte por la interacción interdisciplinar. Toropinto es referido por Cruz para hacer mención de como en los últimos cinco años se observa una resistencia menor de los empresarios mexicanos a invertir en el diseño, y que es una cuestión de tiempo para que el diseño sea reconocido y remunerado de manera apropiada.

Como referencia, el portal de Forbes, con información del Instituto Mexicano de la Competitividad, resume así el crecimiento de la industria creativa nacional:

Se estima que en México cerca de $7 \%$ del PIB provino de las industrias creativas en los últimos 10 años y que ha crecido un $0.18 \%$ en este periodo. Se calcula que, de crecer de acuerdo con su potencial y probabilidades, las industrias creativas podrían tener un incremento en los próximos años de entre $3 \%$ y $4 \%$ anual. Para dar una idea más específica, podemos utilizar el diseño de interiores. Esta industria representa el 0.14 del PIB. Sin embargo, se encuentra a la alza con una expansión 
anual estimada de $20 \%$. Diseño en sus diferentes ramas es la tercera carrera a nivel nacional con mayor incursión de jóvenes: 46 \% (Quesada, 2016, párr. 3).

Cabe destacar que la Ciudad de México fue denominada capital mundial del diseño en el año 2018, además de ser el lugar donde radican diseñadores de gran renombre internacional. También, es la primera metrópoli en Latinoamérica en ser galardonada como sede de la publicación en plataforma web: Design Week. Emilio Cabrero, director de dicho evento, comentó al respecto: «este tipo de eventos posiciona a México y a los participantes en el plano internacional. Posiblemente traiga una inversión significativa. La idea es dar a conocer nuestra aportación al diseño internacional y que haya intercambios culturales» (Quesada, 2016, párr. 2). En el mismo sentido es importante destacar que México es considerado como uno de los países que más aporta al diseño en procesos y materiales (Quesada, 2016). Teniendo en cuenta que en la gráfica artesanal y cultural se integran tendencias globales y nacionales las cuales generan una identidad particular.

Avances científicos y tecnológicos de la disciplina
Es importante mencionar ahora, la relación y la aportación del diseño gráfico hacia la sociedad. Uno de los objetivos de esta disciplina es el desarrollo de una comunicación gráfica responsable y efectiva. Otro es, facilitar este hecho empleando un lenguaje gráfico multicultural. Por lo que se puede decir que, el diseño es un instrumento social. Ya que, suma en su comunicación un uso informativo y de concienciación, entre otras funciones.

Históricamente es importante referir a la Revolución Industrial como uno de los fenómenos impulsores del nacimiento del diseño gráfico. En razón de los procesos de industrialización y de producción a partir de los cuales se sustituyó la producción manual. Esto conllevó por ejemplo, a la evolución de la impresión publicitaria masiva trascendiendo la comunicación a gran escala. Se puede decir entonces que, a partir de este momento histórico, los avances de los medios publicitarios se valorarían con relación a su desarrollo técnico como lo refiere Obregón (2017).

Desde sus orígenes, el diseño gráfico ha comprendido en sus ejes de formación curricular: los campos de la tecnología; la investigación científica y humanista; los procesos y las metodologías; la comunicación y el arte. Actualmente, se puede decir que como industria basa su desarrollo y su producción en las tecnologías. Por citar un ejemplo, está el uso de los sistemas de software para la materialización de las ideas del diseñador. Muestra de este empleo es la impresión 3D que se basa en un procesador de inteligencia artificial que evolucionó hasta considerar el uso mínimo de recursos y ser capaz de reciclarlos en otras producciones (Escuela Superior de Diseño de Barcelona, 2019). 
Estas observaciones se relacionan con la ingeniería de software, área con un elevado desarrollo tecnológico. El diseñador tiene un campo en el cual establecer una vinculación interdisciplinaria, la usabilidad en beneficio del usuario. Algunos expertos debaten sobre los límites de las disciplinas que han de formar a los ingenieros en diseño, pero este es un planteamiento abierto, véase como lo ofertan algunas universidades:

En ambas especializaciones (UX y UI) los límites entre el Diseño y la Ingeniería se vuelven borrosos, y, de hecho, hoy en día se las estudia como posgrados de Ingeniería o Ciencias de la Computación. Esos posgrados están formando programadores de diseño, sin anunciarlo abiertamente (Betancourth, 2019, párr. 4).

Esto refleja la evolución de la relación entre la tecnología y el diseño, traspasando disciplinas y dimensiones. Si bien el acceso a la información de manera masiva ha permitido el manejo de gráficos y el auto-aprendizaje de programas de diseño. Es necesario tener presente que hay un profesional especialista en alfabetización visual, composición, habilidades creativas, metodologías enfocadas en hacer eficiente los resultados y los procesos, el diseñador gráfico. Experto que emplea entre otras herramientas: plumas digitales, pantallas con capacidad de interacción táctil, ordenadores con mayor capacidad para procesamiento de gráficos de gran formato, entre otras.

Por otro lado, la neurociencia cognitiva enfocada se utiliza como instrumento en el proceso de investigación en el branding, la publicidad y otros rubros. Existen diversas nociones respecto a este campo del conocimiento. Para objeto de este estudio, la neurociencia se puede definir como «la disciplina que busca entender cómo la función cerebral da lugar a las actividades mentales, tales como la percepción, la memoria, el lenguaje e incluso la conciencia» (Escera, 2004, 2). En el campo de diseño gráfico se puede considerar la aplicación de los conocimientos de la neurociencia para potenciar la generación y recepción de mensajes gráficos. Ejemplo de esto es, el de la divulgación del conocimiento a través de las infografías y la visualización de los datos científicos que permiten una explicación a partir del uso iconográfico y codificado de los elementos legibles y analogías que buscan un lenguaje visual asertivo para el entendimiento común.

Es dentro de este marco de gran acceso tecnológico que se presenta una evolución en modelos y métodos de trabajo. Avances basados, particularmente como apunta Martin-Iglesias (2011) en la conjunción del internet y la web 2.0, la que ha hecho más fácil y ágil la colaboración entre profesionales, científicos, hombres de negocios, etcétera. Esto puede plantear la idea de un diseño performativo, donde interesa el proceso casi tanto o más que el objeto. El diseño colaborativo puede darse en muchos sentidos, según un estudio de la Universidad Autónoma de Barcelona realizado por Costa $(2015,15)$ se presenta: 
1) con diferentes dinámicas de colaboración (participación, cooperación, interacción),

2) desde la jerarquía y modos de relación entre los agentes implicados (diseñadores, usuarios, clientes),

3) en las distintas fases del desarrollo proyectual (análisis, proceso creativo, implementación) y

4) desde diversas disciplinas (industrial, gráfico, sistemas).

Es el Design Thinking (DT) una referencia principal del diseño colaborativo, «un modelo novedoso y útil para el ejercicio proyectual en diseño y otras áreas donde se busca la innovación» (Tiburcio, 2017, 157). Es importante resaltar entonces, el impacto de la ciencia y la tecnología en los grandes avances del diseño. Ya que, al crear nuevos medios digitales de comunicación ha permitido que los diseñadores desarrollen su creatividad.

Análisis de la disciplina y sus futuras tendencias
El diseñador gráfico actúa como un mediador entre el usuario y el mensaje. Paralelamente es un gestor de proyectos, por lo que adquiere las competencias que sumen a su formación integral. Su papel va más allá de lo técnico, es un socializador del conocimiento que desarrolla el diseño de la experiencia y los procesos de creación. El diseño gráfico se deriva de la comunicación visual, la cual emplea un lenguaje visual como mensaje. De aquí surgen términos como comunicación gráfica y comunicación sígnica, entre otras. Vilchis refiere a la comunicación visual como proceso de diálogo entre un emisor y un receptor entienden el mismo lenguaje:

La comunicación gráfica se entiende como un proceso dialógico porque en la trayectoria de la acción comunicativa, se manifiesta una serie de momentos que establecen las condiciones de diálogo. Per se un discurso visual es un discurso representado y directo cuya estrategia incluye el diálogo entre el emisor que se encuentra en el texto visual mismo -al cual se entiende como emisor interno que, además de ser virtual, puede estar identificado indistintamente con una persona, un objeto, una marca o lo que sea que dice algo a alguien-, y que como en toda relación dialógica, pone el énfasis en el receptor pretendiendo la distancia mínima entre ambos $(2016,17)$.

Es decir, señala la importancia de la emisión de signos codificados en un discurso visual. El cual pretende un entendimiento de su lenguaje sin interpretaciones ambiguas. Considera las aportaciones de los elementos sociales para desarrollar dicho código, de manera que pueda lograrse el diálogo en la interpretación. 
Por otro lado, habría que reconocer el impacto que tienen estos mensajes visuales en el comportamiento de un individuo:

El diseño de comunicación visual se ocupa de la construcción de mensajes visuales con el propósito de afectar el conocimiento, las actitudes y el comportamiento de la gente. Una comunicación llega a existir porque alguien quiere transformar una realidad existente en una realidad deseada (Frascara, 2011, 2).

Como se puede observar el autor enfatiza la transformación del contexto por la comunicación visual. Asimismo, su definición deja en claro el carácter social y la necesidad de concientizar sobre el impacto que esta tiene de alguna manera sobre la educación de los individuos. En este sentido, el diseño gráfico es materia de interpretación para el receptor, acto condicionado por su contexto cultural y personal. El modo de percibir el mundo, la formación, la simbología son elementos que intervienen en la codificación y en la decodificación de la comunicación social.

En respuesta a las distintas preocupaciones que existen sobre el futuro del diseñador gráfico, Davis (2020) expuso en la asociación y comunidad más grande de profesionistas del diseño, The Professional Association for Design, identificada por sus siglas (AIGA) un estudio prospectivo del periodo que comprende del 2016 al 2026 algunos fenómenos que experimentará la profesión. Entre los datos que presentó dio referencia a: la adaptabilidad y al manejo en el uso de sistemas de información complejos, así como a la transición de velocidad del cambio tecnológico. Señaló el uso de programas para la producción de diseño y lo extremadamente rápidas que son las actualizaciones de estos. Esto conlleva por un lado a pensar sobre la continua adaptabilidad a través del autoaprendizaje y a unir experiencias físicas y digitales; por otro lado, implica la responsabilidad de anticipar resultados de diseño con valores éticos. La misma autora considera una evolución hacia el diseño de experiencias, que requiere de un conocimiento del marco político y económico en las empresas.

Otro punto planteado por Davis es el trabajo realizado por el diseñador gráfico durante las últimas décadas, el cual ha estado enfocado al desarrollo de mensajes, de productos y de ambientes con una función particular o bien, orientado a mejorar determinada imagen. También señala que en este periodo industrial y tecnológico, el perfil de empleo del diseñador presenta importantes cambios. Para tal perspectiva Davis cita la proyección del Manual de Perspectivas Ocupacionales 2016-2026, Oficina de Estadísticas Laborales Departamento de Trabajo de los Estados Unidos, y de acuerdo con tal referencia subraya que los trabajos con mayor demanda serán: en primer lugar, el diseñador de software como responsable de los aspectos creativos y la programación; en segundo lugar, el diseñador web encargado de las comunicaciones en redes; en tercer lugar, el director de arte como gestor creativo; y finalmente, el diseñador gráfico especializado para la realización de trabajos de impresión e identidad corporativa. 
En general, los estudios refieren a las actuales condiciones y oportunidades para el diseñador gráfico y otros profesionistas. Durante un estudio dado en el Foro Económico Mundial en el 2018, fueron señaladas las principales habilidades demandadas por los empleadores en el 2020. Entre otras, se encuentran: la resolución de problemas complejos, el pensamiento crítico, la creatividad, el desarrollo de productos, la coordinación de equipos en modalidades virtuales y presenciales, la inteligencia social y emocional, el juicio y la toma de decisiones, la orientación al servicio, la negociación, la flexibilidad, las ventas, la mercadotecnia, y el contenido de redes.

En otro sentido, el Grupo Intergubernamental de Expertos sobre el Cambio Climático (2014) planteó la necesidad de desarrollar un diseño con base en modelos de desarrollo sustentable. Esto en atención a una población mundial que enfrenta los efectos del llamado cambio climático, y en la cual se reportan que las emisiones de gases de efecto invernadero producidos por causas antropogénicas son las más elevadas de la historia. Como define Pelta (2013), el desafío no es solo ambiental, es además económico. Dado a que, están en aumento los índices de pobreza, miseria y condición de desigualdad, en la cual viven un $85 \%$ de la población. Los diseñadores deben educarse con el conocimiento de las tendencias de diseño gráfico sustentable, eco-diseño, diseño verde, diseño socialmente responsable y otros afines.

Este discurso tiene sus antecedentes en la década de los setenta, con Papanek, promotor y pionero del diseño responsable y ambientalmente amigable. Incluso antes de que existiera el término sustentable, había incorporado en su obra Design for the Real World. Human Ecology and Social Change, tanto en la primera como en la segunda edición, una serie de discursos contra el consumismo y una crítica sobre cómo el diseño adoptaba este modelo. Campi (2015) realiza una revisión de la obra de Papanek y encuentra que sus tesis son cercanas a los conceptos hoy nombrados como: diseño funcional, sencillo, incluso honesto; apartado de lo que sucedía en esa generación, acusando que el diseñador es irresponsable desde el momento en que atiende sin objeción, los designios de una industria igualmente irresponsable.

Consideramos que dos aspectos a reflexionar desde el estricto orden del ejercicio profesional del diseño gráfico y la sustentabilidad. Primero, son inminentes llevar a cabo cambios en la concepción y gestión del diseño, el conocimiento de nuevos materiales y formas de trabajo; por lo que es necesario impulsar la investigación y el trabajo colaborativo con otras disciplinas ambientales. Segundo, es imperante el desarrollo de una comunicación visual dirigida a una comunidad general como parte de una estrategia sobre educación ambiental y divulgación científica; aunque no está muy claro cómo estrechar este puente entre los diseñadores, la comunidad científica y el sector gubernamental a cargo de estas tareas.

Tocante al primer aspecto, la gestión sustentable del diseño consideramos que el diseñador tiene un compromiso ineludible en su práctica 
mediante las actividades realizadas ante una producción desmedida, resultado de las exigencias del mercado basado únicamente en un análisis de las necesidades individuales y la competencia mercantil. Por ello, el diseñador debe estar capacitado para incorporar una visión de cuidado del medio ambiente Vilchis (2015). En cuanto al segundo aspecto, la aportación discursiva los diseñadores gráficos pueden informar y concientizar al público sobre los problema ambientales y sus soluciones de acuerdo con Pelta (2013). El propósito sería cambiar hábitos y generar una conciencia de consumo más acorde a las condiciones actuales del planeta, planteando una relación más equilibrada entre individuo-naturaleza.

El diseño debe articular en sus programas de formación una educación ambiental. Aunque como mencionan Dieleman \& Juárez-Nájera (2008) esto es una lucha de paradigmas, aquí se plantean conceptos al parecer sencillos como ¿qué es la naturaleza?, ¿qué es lo sostenible?, y ¿cómo pueden ser enseñados y aprendidos estos conceptos? Todos los que están participando de las políticas y de la comunicación ambiental, son parte del problema pues tienen diferentes valores y creencias. Entonces, el diseñador debe estar habilitado para comunicar conceptos ambientales con un lenguaje acertado. Súmese a esto, la dificultad de los científicos para generar información accesible a la población, ello conlleva hacia una indiferencia. Igualmente, Dieleman \& Juárez-Nájera hacen alusión a Sauvé (1996) para señalar un ejercicio que realizó en la identificación de las principales maneras en las que se concebía el concepto ambiente, a partir de las cuales platean estrategias de enseñanza-aprendizaje. Por ejemplo, si la naturaleza era concebida como un recurso, se trabajaría con la campaña de las $3 R$ (reducir, reutilizar y reciclar) o si el ambiente era parte de un proyecto de comunidad se presentaría con narraciones. Posibilidades que pueden ser materializadas por el diseñador.

Sumando lo anterior, destacamos tres elementos de cambio propuestos por Vilchis (2005) aplicables a la formación y al desarrollo profesional del diseñador gráfico y disciplinas afines. En primera instancia, la autora destaca la necesidad de formar una conciencia sobre el uso de los recursos en el diseño, diferenciando los recursos renovables o de los recursos no renovables; conocer los tiempos de biodegradación y su potencial incorporación a procesos de reúso o reciclaje. En segundo lugar, refiere a la importancia de discutir el diseño innecesario, promover la innovación sustentable, apoyar la tendencia del consumidor ecológico, encontrar nichos de diseño gráfico responsable. Además, otro factor que señala es el implicarse en la reducción de impresiones de volantes, folletos, envolturas, empaques, entre otros. Así como también, reflexionar sobre las necesidades generadas o provocadas por el diseño. Es decir, el diseñador gráfico debe cuestionar cómo su praxis contribuye a la formación de necesidades ficticias, hábitos de consumo irracional y sobreconsumo, haciendo un esfuerzo por cambiarlos por una difusión sustentable.

En este último sentido, existen guías de consulta abierta o iniciativas para acercarse al camino de la sustentabilidad, como: Re-nourish, The 
Designers Accord, Creative for a Cause y Design can Change esto de acuerdo con Pelta (2013). A través de estas guías, los diseñadores gráficos han dejado evidencia de un discurso con tendencia a un pensamiento sostenible. Aunque, son particularmente de habla no hispana. Es preciso valorar el alto sentido de la responsabilidad y el reconocimiento de estas iniciativas alejadas de la remuneración económica, planteadas como una ventana discursiva.

Conclusiones A más de 50 años de haberse celebrado los Juegos Olímpicos en México y de haber sido reconocidos por el trabajo de iconografía realizado, lo que traería consigo la proyección internacional de la herencia de la cultura gráfica mexicana y la creación de la carrera de Diseño Gráfico. Sin embargo, hasta la fecha y a pesar de la evolución de las industrias creativas, todavía se enfrenta al reto de profesionalizar la disciplina en función de equiparar su valor con estándares internacionales. Pese a que México ha sido posicionado como una referencia mundial, en eventos como Design Week o por su desarrollo de áreas como el diseño web y multimedia, el diseño de software y de videojuegos.

La gran escalada tecnológica posiciona al diseñador gráfico como un comunicador de mensajes visuales, quien en un futuro inmediato deberá responder a la resolución de problemas complejos como: el desarrollo de productos, el conocimiento de ingeniería y computación pertenecientes de la disciplina, la aplicación de modelos de colaboración para la gestión de procesos y de equipos de trabajo, la gestión de proyectos, la identificación de oportunidades en el trabajo multidisciplinario como es la ingeniería de software, la experiencia de usuario, entre otros. Encontrar, además, una mayor interacción con distintas culturas y ampliar los conocimiento de las leyes que regulan la profesión. También, aprovechar la tecnología para lograr mayor eficiencia en los procesos de producción, los soportes de los procesos manuales, y el uso de herramientas tecnológicas, como potenciadoras de la fase creativa.

La inclusión del diseñador en el trabajo multidisciplinario como lo es la ingeniería de software, llevará a romper límites de la comunicación en los entornos virtuales. Por otro lado, la divulgación de la ciencia en función de socializar el conocimiento a partir del uso de infografías, es realmente indispensable en un contexto de deterioro social y ambiental. El trabajo del diseñador gráfico puede trascender incluso en la divulgación que desarrolla por iniciativa propia y sin un propósito económico, de manera colectiva o individual. En suma, esta coyuntura mundial abre nuevas posibilidades de participación a los profesionistas de una disciplina en la que se afronta el gran reto de no perder la esencia de comunicar. 
Referencias Balcázar, M. (Marzo, 2019). Cómo se creó la identidad de los Juegos Olímpicos México 68. [Foro Alfa, sitio web] Recuperado de: https://foroalfa.org/ articulos/como-se-creo-la-identidad-de-los-juegos-olimpicos-mexico-68

Betancouth, M. (15 de julio 2019). De diseñador a programador de diseño. [Foro Alfa, sitio web] Recuperado de: https://foroalfa.org/articulos/dedisenador-a-programador-de-diseno

Campi, I. (2015). Victor Papanek. Diseñar para el mundo real y su contexto. Victor Papanek, textos en torno a un diseñador crítico. 10-33. Barcelona: Pol·len Edicions-Monográfica.

Costa, T. (2015). Los procesos creativos en el diseño colaborativo (1. ${ }^{a}$ parte). Diseño participativo. Journal of design processes. 1(1), 89-101. Recuperado de https://diposit.eina.cat/handle/20.500.12082/704?show=full

Cruz, C. (2018). Los diseñadores comparten inquietudes y malas prácticas en la cultura del diseño gráfico en México. [CoolHunterMx, sitio web]. Recuperado de: https://coolhuntermx.com/diseno-grafico-mexicoproblemas-comunidad-diseno/

Davis, M. (2020). Introduction to Design Futures. [AIGA, sitio web]. Recuperado de https://www.aiga.org/aiga-design-futures/introductionto-design-futures/

Dieleman, H., y Juárez-Nájera, M. (2008). ¿Cómo se puede diseñar educación para la sostenibilidad? Revista Internacional de Contaminación Ambiental. 24 (3), 131-147. Recuperado de http://www.scielo.org.mx/scielo. php?script=sci_arttext\&pid=S0188-49992008000300004

Escera, C. (2004). Aproximación histórica y conceptual a la Neurociencia Cognitiva. Cognitiva. 16 (2) 141-162.

Escuela Superior de Diseño de Barcelona. (2019). El avance de las impresoras 3D y su uso en el mundo del diseño. [EsDesign, sitio web]. Recuperado de https://www.esdesignbarcelona.com/int/expertos-diseno/el-avancede-las-impresoras-3d-y-su-uso-en-el-mundo-del-diseno

Foro Económico Mundial. (2019). Jobs of Tomorrow Mapping Opportunity in the New Economy. Recuperado de: http://www3.weforum.org/docs/ WEF_Jobs_of_Tomorrow_2020.pdf

Frascara, J. (2011). Diseño gráfico para la gente. Argentina: Ediciones Infinito.

Grupo Intergubernamental de Expertos sobre el Cambio Climático. (2014). Climate Change 2014 Synthesis Report. [IPCC, artículo en internet]. Recuperado de https://archive.ipcc.ch/news_and_events/docs/ar5/ ar5_syr_headlines_en.pdf

Guyot, C. (1 de junio 2008). El diseño socializa el conocimiento. La Nación. Recuperado de https://www.lanacion.com.ar/opinion/joan-costa-eldiseno-socializa-el-conocimiento-nid1017188

Kloss Fernández del Castillo, G. (20 de octubre de 2006). Algunos apuntes históricos sobre las escuelas de diseño. [Encuadre, sitio web]. Recuperado de https://encuadre.org/algunos-apuntes-historicos-sobre-las-escuelasde-diseno/

Martin-Iglesias, R. (Noviembre, 2011). Hacia un nuevo paradigma de Diseño Colaborativo. 1-4. Recuperado de http://papers.cumincad.org/data/ works/att/sigradi2011_245.content.pdf 
Obregón, A. (2017). La revolución industrial y el diseño gráfico. [Publicado en un blog]. Recuperado de https://historiadeldisenograficoblog.wordpress. com/2017/03/27/la-revolucion-industrial-y-el-diseno-grafico/

Pelta, R. (2013). Ver para creer. Diseño, ilustración y sostenibilidad. Valencia, España: UPV. Recuperado de https://polipapers.upv.es/index.php/eme/ article/view/1480/1536

Quesada, J. (26 de diciembre 2016). México, meca del diseño mundial. [Forbes, sitio web] Recuperado de https://www.forbes.com.mx/forbes-life/ mexico-meca-del-diseno-mundial/

Sauvé, L. (1996). Environmental education and sustainable development: A further appraisal. Canadian Journal of Environmental Education. 1 (1), 7-33.

Tiburcio, C. (2017). Cuestiones de hecho y cuestiones de procedimiento. ¿Design Thinking? Una discusión a nueve voces. A. Tapia (coord.). 154159. México: Ars Optika Editores.

Vilchis, L. (2015). Diseño gráfico sustentable. México: CEID.

Vilchis, L. (2016). La semiosis de la hermeneútica de los lenguajes gráficos no lineales. México: Qartuppi.

\section{Sobre los autores Susana Rodríguez Gutiérrez}

Doctorante en Artes y Diseño por la Universidad Autónoma de México, su línea de investigación es la comunicación visual y la semiótica. Maestra en Diseño Gráfico y Comunicación por la Universidad Iberoamericana Tijuana (UIA) y licenciada en Diseño por la Universidad Xochicalco (CEUX). Ponente nacional e internacional en coloquios de relevancia. Publicaciones y arbitrajes en revistas nacionales sobre las áreas del conocimiento en semiótica, comunicación visual y diseño gráfico. Actualmente es profesor investigador de tiempo completo en la Universidad Autónoma de Baja California (UABC) y miembro del cuerpo académico, Diseño y Comunicación. Recibió el reconocimiento perfil PRODEP (2019-2022).

\section{Carolina Trejo Alba}

Doctora en Diseño y Estudios Urbanos por la Universidad Autónoma Metropolitana-Azcapotzalco, maestra en Administración Integral del Ambiente por el Colegio de la Frontera Norte y arquitecta por el Instituto Tecnológico de Tepic. Actualmente es profesora investigadora de tiempo completo en la Universidad Autónoma de Baja California (UABC). Además es líder del cuerpo académico, UABC-CA-201 Diseño Integral Ambiental. Catedrática en el programa de posgrado multisede de la maestría y del doctorado en Arquitectura, Urbanismo y Diseño del programa educativo de Arquitectura. Recibió el reconocimiento perfil PRODEP (2018-2021). 


\section{Ervey Leonel Hernández Torres}

Doctor en Diseño y Visualización de la Información por la Universidad Autónoma Metropolitana (UAM), maestro en Educación enfocada a Diseño de Nuevas Tecnologías por la Universidad Interamericana para el Desarrollo y licenciado en Comunicación por la Universidad Autónoma de Baja California (UABC). Su especialidad es el Diseño y Creación de Videojuegos por la Universidad Autónoma de Barcelona. Actualmente es profesor investigador de tiempo completo en la Universidad Autónoma de Baja California. Miembro del cuerpo académico, Diseño y Comunicación, presidente del SACC de Diseño y Comunicación del doctorado en Arquitectura, Urbanismo y Diseño. Catedrático en el posgrado de Diseño y la licenciatura en Diseño Gráfico. Miembro del Sistema Nacional de Investigadores, nivel candidato (2020-2023). Recibió el reconocimiento perfil PRODEP (2019-2022). Miembro de la Red Iberoamericana de Investigación Multidisciplinaria de Videojuegos. 